\title{
Adiponectin and Its Receptors Are Differentially Expressed in Human Tissues and Cell Lines of Distinct Origin
}

\author{
Simon Jasinski-Bergner ${ }^{a}$ Maximilian Büttner ${ }^{a} \quad$ Dagmar Quandt $^{b}$ \\ Barbara Seliger $^{b}$ Heike Kielstein ${ }^{a}$ \\ ${ }^{a}$ Institute of Anatomy and Cell Biology, Faculty of Medicine, Martin Luther University Halle- \\ Wittenberg, Halle (Saale), Germany; ${ }^{b}$ Institute of Medical Immunology, Faculty of Medicine, \\ Martin Luther University Halle-Wittenberg, Halle (Saale), Germany
}

\section{Keywords}

$\mathrm{CDH} 13 \cdot$ AdipoQ $\cdot \mathrm{T}$ cadherin $\cdot$ Adiponectin $\cdot$ Expression

\begin{abstract}
Background: Adiponectin is secreted by adipose tissue and exerts high abundance and an anti-inflammatory potential. However, only little information exists about the expression profiles of adiponectin and its recently identified receptor $\mathrm{CDH} 13$ in non-tumorous human tissues and their association to clinical parameters. Methods: The expression levels of adiponectin and $\mathrm{CDH} 13$ were analyzed in heart, liver, kidney, spleen, skin, blood vessels, peripheral nerve and bone marrow of 21 human body donors, in 12 human cell lines, and in purified immune effector cell populations of healthy blood donors by immunohistochemistry, Western-blot, and semi-quantitative PCR. The obtained results were then correlated to clinical parameters, including age, sex and known diseases like cardiovascular and renal diseases. Results: Adiponectin expression in renal corpuscles was significantly higher in humans with known renal diseases. A coordinated expression of adiponectin and CDH13 was observed in the myocard. High levels of adiponectin could be detected in the bone marrow, in certain lymphoid tumor cell lines and in purified immune effector cell populations of healthy donors, in particular in cytotoxic T cells. Conclusion: For the first time, the expression profiles of adiponectin and $\mathrm{CDH} 13$ are analyzed in many human tissues in correlation to each other and to clinical parameters.

(c) 2017 The Author(s)

Published by S. Karger GmbH, Freiburg
\end{abstract}


Jasinski-Bergner et al.: Adiponectin and Its Receptors Are Differentially Expressed in Human Tissues and Cell Lines of Distinct Origin

\section{Introduction}

The increasing worldwide health problems overweight (BMI $\geq 25 \mathrm{~kg} / \mathrm{m}^{2}$ ) and obesity $\left(B M I \geq 30 \mathrm{~kg} / \mathrm{m}^{2}\right)$ negatively affect the patients in various manners. The pure weight of the fat mass damages joints and increases the risk for an artificial hip and knee joint implantation [1]. Furthermore, the associated lack of exercise and systemic metabolic dysfunctions promote a couple of diseases like type 2 diabetes, fatty liver disease, atherosclerosis, and cardiovascular disorders and herewith a significantly reduced life expectancy [2, 3].

In addition, the adipose tissue secretes various hormones, the so-called adipokines. These secreted molecules enable a communication between adipose tissue, other organs and tissues, including liver, kidney, skeletal muscle, heart, brain, and vasculature [4-6]. In a status of obesity and overweight, an altered expression pattern of such adipokines can be found. So far, about 600 proteins potentially secreted by adipose tissue have been identified in the secretome of adipose tissue and characterized for their putative role in cell signaling and metabolism [7].

Interestingly, several adipokines exert an anti- or even a pro-inflammatory role linking adiposity with immunologic processes. Indeed, obesity increases the risk for certain tumor diseases, including colorectal cancer, renal cancer, post-menopausal breast cancer, and prostate cancer [8]. While the adipokines leptin and resistin represent two out of many proinflammatory adipokines, the number of known anti-inflammatory adipokines is lower [2]. The best characterized anti-inflammatory adipokine is adiponectin [9], which is also the most abundant adipokine within the human body [8]. Adiponectin acts anti-inflammatory by interfering the functions of macrophages, T lymphocytes, and NK cells [10-13].

The gene of adiponectin is located on the long arm of chromosome 3 (3q27). The encoded protein is about $30 \mathrm{kDa}$ and exists in cells and in the plasma in three major forms (homomultimers): trimers (LMW; $67 \mathrm{kDa}$ ), hexamers (MMW; $136 \mathrm{kDa}$ ) and high-molecular-weight (HMW; >300 kDa) multimers [14]. Interestingly, the different protein forms act as ligands for different receptors: the trimer is bound by the adiponectin receptor 1 (AdipoR1), and the hexamer is bound by the adiponectin receptor 2 (AdipoR2). Furthermore, the adiponectin hexamers and the HMW multimers, but not the adiponectin trimers, act as ligands for T-cadherin (CDH13) $[15,16]$.

Since only eukaryotically expressed adiponectin binds to T-cadherin, posttranslational modifications of adiponectin might be critical for that interaction [16]. In contrast to most classical members of the cadherin receptor family, $\mathrm{CDH} 13$ lacks the intracellular domain and the determinant sequence to mediate cell-cell adhesion via strand-swapped-dimer formation that is typical for most cadherins $[17,18]$. CDH13 exerts a pro-angiogenic function, which has been observed in a murine mammary tumor model, whereas its deficiency limited tumor neovascularization, resulting in significantly reduced tumor growth [19]. Furthermore, mice lacking adiponectin or CDH13 expression showed exaggerated cardiac hypertrophy and accelerated decompensation after transaortic constriction-induced pressure overload as compared to wild-type mice [20]. A downregulation of CDH13 due to loss of heterozygosity or hypermethylation has been reported in certain human tumor diseases, such as breast, lung, colorectal, gastric and nasopharyngeal carcinomas, retinoblastoma, and pituitary adenomas [21].

In this study we investigate the expression of adiponectin and its known receptor CDH13, including the six different CDH13 protein coding mRNA isoforms, in human tissues of human body donors and in a set of different human cell lines as well as in different immune effector cell populations, including $\mathrm{T}$ helper (Th) cells, cytotoxic T lymphocytes (CTLs), natural killer (NK) cells, B cells and monocytes, isolated from peripheral blood of healthy blood donors. The expression profiles were correlated to each other and to certain clinical parameters, including 
Jasinski-Bergner et al.: Adiponectin and Its Receptors Are Differentially Expressed in Human Tissues and Cell Lines of Distinct Origin

age, sex, and known diseases. These data fill a gap due to the fact that so far only little human expression data of non-tumorous samples exists about adiponectin and its recently identified receptor $\mathrm{CDH} 13$.

\section{Material and Methods}

\section{Cell Lines and Cell Culture}

The human embryonal kidney cell line HEK293T $\left(\right.$ ATCC $^{\circledR}$ CRL-3216 ${ }^{\mathrm{TM}}$ ) and the other cell lines were purchased from the American Type Culture Collection (ATCC; Manasas, VA; USA). All adherent cell lines were cultured in Dulbecco's modified Eagles medium (DMEM; Thermo Fisher Scientific, Waltham, MA, USA) supplemented with $10 \%$ (V/V) fetal bovine serum, 2 mmol/l L-glutamine (Lonza, Basel, Switzerland), $1 \%$ penicillin/streptomycine (V/V; PAA, Pasching, Austria), and 25 mmol/l HEPES (c-c-pro, Oberdorla, Germany). The SGBS pre-adipocyte cells were cultured in a medium as published by Wabitsch et al. [22].

All suspension cell lines were cultured in RPMI 1640 medium (Thermo Fisher Scientific) supplemented with $10 \%$ (V/V) fetal bovine serum, $2 \mathrm{mmol} / \mathrm{l} \mathrm{L-glutamine} \mathrm{(Lonza),} 1 \%$ penicillin/streptomycine (V/V; PAA), and $25 \mathrm{mmol} / \mathrm{l}$ HEPES (c-c-pro).

\section{RNA Extraction, cDNA Synthesis and qPCR}

Total RNA was extracted from cell pellets employing TRIzol Reagent (Thermo Fisher Scientific), digested with DNase I (Promega, Mannheim, Germany) and applied for cDNA synthesis utilizing the RevertAidTM H Minus First Strand cDNA synthesis kit (Thermo Fisher Scientific) as recently described [23].

All applied oligonucleotides are listed in the table 1. All semi-quantitative PCR reactions and the CDNA syntheses were performed in a Biometra T3000 (Biometra, Göttingen, Germany) thermocycler.

Resulting semi-quantitative PCR products were size fractionated on $2 \%(\mathrm{w} / \mathrm{V})$ ethidium bromidecontaining agarose gels.

\section{Protein Extraction and Western-Blot Analysis}

Proteins were extracted from frozen cell pellets with xTractor buffer (Clontech) supplemented with protease inhibitor cocktail (Sigma-Aldrich, St. Louis, MO, USA). The proteins were analyzed by Western-blot using $50 \mu \mathrm{g}$ of total protein/lane. For Western-blot analyses, the following primary antibodies were applied: murine monoclonal anti-adiponectin (19F1) (Abcam, Cambridge, UK), murine monoclonal anti- $\beta$-actin (AC-15) (Sigma-Aldrich), rabbit monoclonal anti-GAPDH [14C10] (Cell Signaling Inc., Cambridge, UK), and rabbit polyclonal anti-CDH13 (Merck Millipore, Billerica, MA, USA). For detection, horseradishperoxidase(HRP)-conjugated secondary antibodies and the Amersham ECL Prime Western-blot Detection Reagent (GE Healthcare Life Sciences, Chalfont St. Giles, UK) were used. The staining was recorded with a CCD camera system (ChemiDoc Touch Imaging System; Bio-Rad).

\section{Immunohistochemistry}

Tissue samples of heart, liver, kidney, spleen and skin were taken from 21 formaldehyde-conserved body donors, embedded in paraffin and cut to $5 \mu \mathrm{m}$ on a microtome (Microm HM400, Microm, Walldorf, Germany).

After incubation at $60^{\circ} \mathrm{C}$ for $4 \mathrm{~h}$, samples were deparaffinized and hydrated. Samples for adiponectin staining then underwent additional epitope retrieval treatment. For this purpose, skin sections were incubated in PBS containing 1\% SDS (w/V) overnight while other samples underwent HIER treatment for $30 \mathrm{~min}$ at $95{ }^{\circ} \mathrm{C}$ in citrate buffer $\mathrm{pH}$ 6.0. Blockade of endogenous peroxidases was reached by incubation in $3 \% \mathrm{H}_{2} \mathrm{O}_{2}$ (V/V) for $20 \mathrm{~min}$ at room temperature. Samples were then blocked in $10 \%$ goat serum (V/V) (Agilent, Santa Clara, CA, USA) for $1 \mathrm{~h}$ at room temperature. Subsequently, they were incubated with the appropriate primary antibody at the dilutions anti-CDH13 (1:1,000; rabbit polyclonal anti-CDH13 (Merck Millipore)) and antiAdipoQ (1:2,500; murine monoclonal anti-adiponectin (19F1) (Abcam)) overnight at $4{ }^{\circ} \mathrm{C}$. The appropriate HRP-linked secondary antibody was purchased from Dako (Santa Clara, CA, USA) and pipetted onto the sample and incubated at room temperature for $1 \mathrm{~h}$.

Washing was performed after peroxidase block and antibody incubations for $3 \times 5 \mathrm{~min}$ in TBS-T. Buffered 3,3'-diaminobenzidine working solution was mixed from DAB+ liquid kit (Dako) and pipetted onto the samples. The reaction was quenched after $5 \mathrm{~min}$ through alkaline $\mathrm{pH}$ shift by immersion of samples in tap water. After hematoxylin counterstain and blueing, samples were dehydrated and mounted using Aquatex mounting medium (Merck Millipore). 
Jasinski-Bergner et al.: Adiponectin and Its Receptors Are Differentially Expressed in Human Tissues and Cell Lines of Distinct Origin

Table 1. Applied oligonucleotides

\begin{tabular}{|c|c|c|c|c|}
\hline Oligonucleotide & Application & Sequence $\left(5^{\prime} \rightarrow 3^{\prime}\right)$ & PCR product & Reference \\
\hline $\begin{array}{l}\text { qPCRAdipoR1fw } \\
\text { qPCRAdipoR1rev }\end{array}$ & $\begin{array}{l}\text { qPCR } \\
\text { qPCR }\end{array}$ & $\begin{array}{l}\text { CCTGCCAGTAACAGGGAAGC } \\
\text { GATGCTCTTGAAGCAAGCCC }\end{array}$ & 339 bp & \\
\hline $\begin{array}{l}\text { qPCRAdipoR2fw } \\
\text { qPCRAdipoR2rev }\end{array}$ & $\begin{array}{l}\text { qPCR } \\
\text { qPCR }\end{array}$ & $\begin{array}{l}\text { CCATAGGGCAGATAGGCTGG } \\
\text { GAATAAGCCAGGGTTTGGGC }\end{array}$ & $489 \mathrm{bp}$ & \\
\hline $\begin{array}{l}\text { qPCRADIPOQfw } \\
\text { qPCRADIPOQrev }\end{array}$ & $\begin{array}{l}\text { qPCR } \\
\text { qPCR }\end{array}$ & $\begin{array}{l}\text { ATGCTGTTGCTGGGAGCTGTTC } \\
\text { TCAGTTGGTGTCATGGTAGAG }\end{array}$ & 717 bp & \\
\hline $\begin{array}{l}\text { sqP\#134CDH13fw } \\
\text { sqP\#134CDH13rev }\end{array}$ & $\begin{array}{l}\text { semi-qPCR } \\
\text { semi-qPCR }\end{array}$ & $\begin{array}{l}\text { GTTCTCCTGTCCCAGGTGC } \\
\text { CTTTCCAGTGAGCCGGAACT }\end{array}$ & $\begin{array}{l}504 \text { bp, } 295 \\
\text { bp, } 387 \text { bp }\end{array}$ & \\
\hline $\begin{array}{l}\text { sqP\#2CDH13fw } \\
\text { sqP\#2CDH13rev }\end{array}$ & $\begin{array}{l}\text { qPCR } \\
\text { qPCR }\end{array}$ & $\begin{array}{l}\text { AGGTGCTCACCCCGTATCT } \\
\text { TGTTCTTGCTGGGGGAACCA }\end{array}$ & $336 \mathrm{bp}$ & \\
\hline $\begin{array}{l}\text { sqP\#5CDH13fw } \\
\text { sqP\#5CDH13rev }\end{array}$ & $\begin{array}{l}\text { qPCR } \\
\text { qPCR }\end{array}$ & $\begin{array}{l}\text { ACTGCAGTGGGCAAAACTCT } \\
\text { GTGGGTTCTCTTGCCAACATC }\end{array}$ & $231 \mathrm{bp}$ & \\
\hline $\begin{array}{l}\text { sqP\#6CDH13fw } \\
\text { sqP\#6CDH13rev }\end{array}$ & $\begin{array}{l}\text { qPCR } \\
\text { qPCR }\end{array}$ & $\begin{array}{l}\text { AGAACTCGTGATTGTCGGGG } \\
\text { GGTTCTCTCTCATGTCAGCCA }\end{array}$ & $217 \mathrm{bp}$ & \\
\hline $\begin{array}{l}\text { qPCRfwGAPDH } \\
\text { qPCRrevGAPDH }\end{array}$ & $\begin{array}{l}\text { qPCR } \\
\text { qPCR }\end{array}$ & $\begin{array}{l}\text { CAAGGTCATCCATGACAACTTTG } \\
\text { GTCCACCACССTGTTGCTGTAG }\end{array}$ & $496 \mathrm{bp}$ & Fermentas \\
\hline $\begin{array}{l}\text { CD4 qPCR fw } \\
\text { CD4 qPCR rev }\end{array}$ & $\begin{array}{l}\text { qPCR } \\
\text { qPCR }\end{array}$ & $\begin{array}{l}\text { GTCCCTTTTAGGCACTTGCTTCT } \\
\text { TCTTTCCCTGAGTGGCTGCT }\end{array}$ & $67 \mathrm{bp}$ & {$[30]$} \\
\hline $\begin{array}{l}\text { CD8 qPCR fw } \\
\text { CD8 qPCR rev }\end{array}$ & $\begin{array}{l}\text { qPCR } \\
\text { qPCR }\end{array}$ & $\begin{array}{l}\text { CCCTGAGCAACTCCATCATGT } \\
\text { GTGGGCTTCGCTGGCA }\end{array}$ & $64 \mathrm{bp}$ & {$[30]$} \\
\hline $\begin{array}{l}\text { CD14 qPCR fw } \\
\text { CD14 qPCR rev }\end{array}$ & $\begin{array}{l}\text { qPCR } \\
\text { qPCR }\end{array}$ & $\begin{array}{l}\text { ACTTATCGACCATGGAGCGC } \\
\text { AGCTCACAAGGTTCTGGCGT }\end{array}$ & $91 \mathrm{bp}$ & {$[30]$} \\
\hline $\begin{array}{l}\text { CD20 qPCR fw } \\
\text { CD20 qPCR rev }\end{array}$ & $\begin{array}{l}\text { qPCR } \\
\text { qPCR }\end{array}$ & $\begin{array}{l}\text { ATGACAACACCCAGAAATTC } \\
\text { TTAAGGAGAGCTGTCATTTTCT }\end{array}$ & 894 bp & {$[31]$} \\
\hline $\begin{array}{l}\text { CD56 qPCR fw2 } \\
\text { CD56 qPCR rev2 }\end{array}$ & $\begin{array}{l}\text { qPCR } \\
\text { qPCR }\end{array}$ & $\begin{array}{l}\text { AAGTCCCTGGACTGGAATGC } \\
\text { TCCATCATGGTTTGGGGTCC }\end{array}$ & 396 bp & \\
\hline
\end{tabular}

As negative control, a staining without the primary antibody and just with the respective secondary antibody was performed.

The scoring of the respective expression profiles were performed by at least two independent investigators.

Isolation of Mononuclear Cells from Human Peripheral Blood and cell Sorting by FACS

Mononuclear cells from peripheral blood of three healthy human donors were isolated by ficoll density gradient according to manufactures instructions. The peripheral blood mononuclear cells (PBMCs) were subsequently stained in two different panels to sort different immune cell populations. Panel 1 and panel 2 contained the following antibodies: panel 1) anti-CD3 PE-Cy7 (clone SK7; BD Pharmingen, San Jose, CA, USA), anti-CD20 APC-H7 (clone L27; BD Pharmingen), anti-CD4 APC (clone RPA-T4; BD Pharmingen), and anti-CD8 PE (clone RPA-T8; BD Pharmingen); panel 2) anti-CD56 APC (clone NCAM16.2; BD Pharmingen), anti-CD14 FITC (clone M $\varphi$ P9; BD Pharmingen), and anti-CD3 PE-Cy7. Parallel FACS sorting of at least $5 \times 10^{5}$ and up to $1 \times 10^{6}$ cells was performed using a FACS Aria Fusion (BD Bioscience). Doublets were excluded by gating, and 
Table 2. General information about the human body donors
Jasinski-Bergner et al.: Adiponectin and Its Receptors Are Differentially Expressed in Human Tissues and Cell Lines of Distinct Origin

\begin{tabular}{llll}
\hline & Male & Female & Total \\
\hline Number & 10 & 11 & 21 \\
Average age, years & 83 & 87 & 85 \\
Known cardiovascular disease & 6 & 7 & 13 \\
Known renal disease & 4 & 2 & 6 \\
Known tumor disease & 2 & 3 & 5 \\
Known type 2 diabetes mellitus & 1 & 3 & 4 \\
\hline
\end{tabular}

the machine was set to 4-way purity modus for sorting. Cell purity was controlled for each cell population by re-analyzing the sorted fractions and was $>99 \%$ for B cells (CD3- CD20+), CD8+ (CD3+ CD8+), CD4+ (CD3+ CD4+) T cells, NK cells (CD3- CD56+) and $>96 \%$ for monocytes (CD3- CD14+). Purity of cell fractions was furthermore controlled by PCR analysis of cell type-specific antigens in downstream PCR analyses.

\section{Human Body Donors}

Tissue samples were collected from 21 formalin/ethanol-fixed body donors during the gross anatomy course in the Institute of Anatomy and Cell Biology, Faculty of Medicine, Martin Luther University HalleWittenberg, Halle, Germany. In table 2 additional information about the human body donors are listed. The cohort was composed of 10 male and 11 female body donors. The age ranged from 74 to 94 years with a mean age of 85 years.

Pathological background information of the body donors were obtained from the certificate of death. At this point we have to admit that these information are often not complete regarding all possible pathologies of the certain human body donor, including diagnosed and so far undiagnosed pathologies.

During preparation course and specimen collection, several medical specialists of anatomy and pathology were present. The skin samples were taken from the gluteal region.

The frozen arm tissue samples were collected from non-formalin/ethanol-fixed body donors. All body donors agreed at lifetime for usage of their mortal remains for medical science and medical teaching.

This study followed the Declaration of Helsinki and was approved by the local ethics committee of the Faculty of Medicine, Martin Luther University Halle-Wittenberg, Halle (Saale), Germany.

Statistical Analysis

Statistical analyses were performed using the two-tailed Students' t-test under assumption of non-equal variance, and $p$ values of $p \leq 0.05$ were considered as significant and labelled with * $(p \leq 0.05)$ and ${ }^{* *}$ with $(\mathrm{p} \leq 0.005)$.

For statistical computing and plotting OriginPro 2016G suite (OriginLab, Northampton, USA) was applied. Evaluation of RT-qPCR data was done using Microsoft Excel 2016 (Microsoft, Albuquerque, USA).

\section{Results}

\section{Adiponectin Expression in Human cell Lines and Frozen human Tissues}

The human SGBS preadipocytes, the human embryonal kidney cell line HEK293T, the colorectal adenocarcinoma cancer cell lines DLD-1 and HT-29, the liver adenocarcinoma cell line SK-HEP-1, the chronic myelogenous leukemia (CML) cell line K562, the B-cell lymphoma cell lines Daudi and Raji, the T-cell leukemia cell line Jurkat and the NK-cell lymphoma cell lines NK-92, NK-L and KHYG-1 were monitored for their adiponectin expression using Western-blot analyses. The murine monoclonal antibody anti-adiponectin (19F1) was applied, detecting different adiponectin quaternary protein structures like monomers, homotrimers, homo-hexamers, and homo-multimers. In fig. 1A, a representative Western-blot is shown with all four AdipoQ-positive cell lines. The adiponectin protein was further investigated by Western-blot in dissected frozen human tissues from arms of human body donors including cutis, subcutis, biceps brachii muscle (Musculus biceps brachii), brachial artery 
(Arteria brachialis), median nerve (Nervus medianus) and bone marrow of the humerus using SGBS cells as positive control (fig. 1B). Interestingly, referring to the results of the tested cell lines, the highest expression within the investigated in vivo tissues was observed in the bone marrow. In contrast, a lower adiponectin expression was detected in cutis, subcutis and muscle, whereas the adiponectin expression in artery and neuronal tissue was only barely to

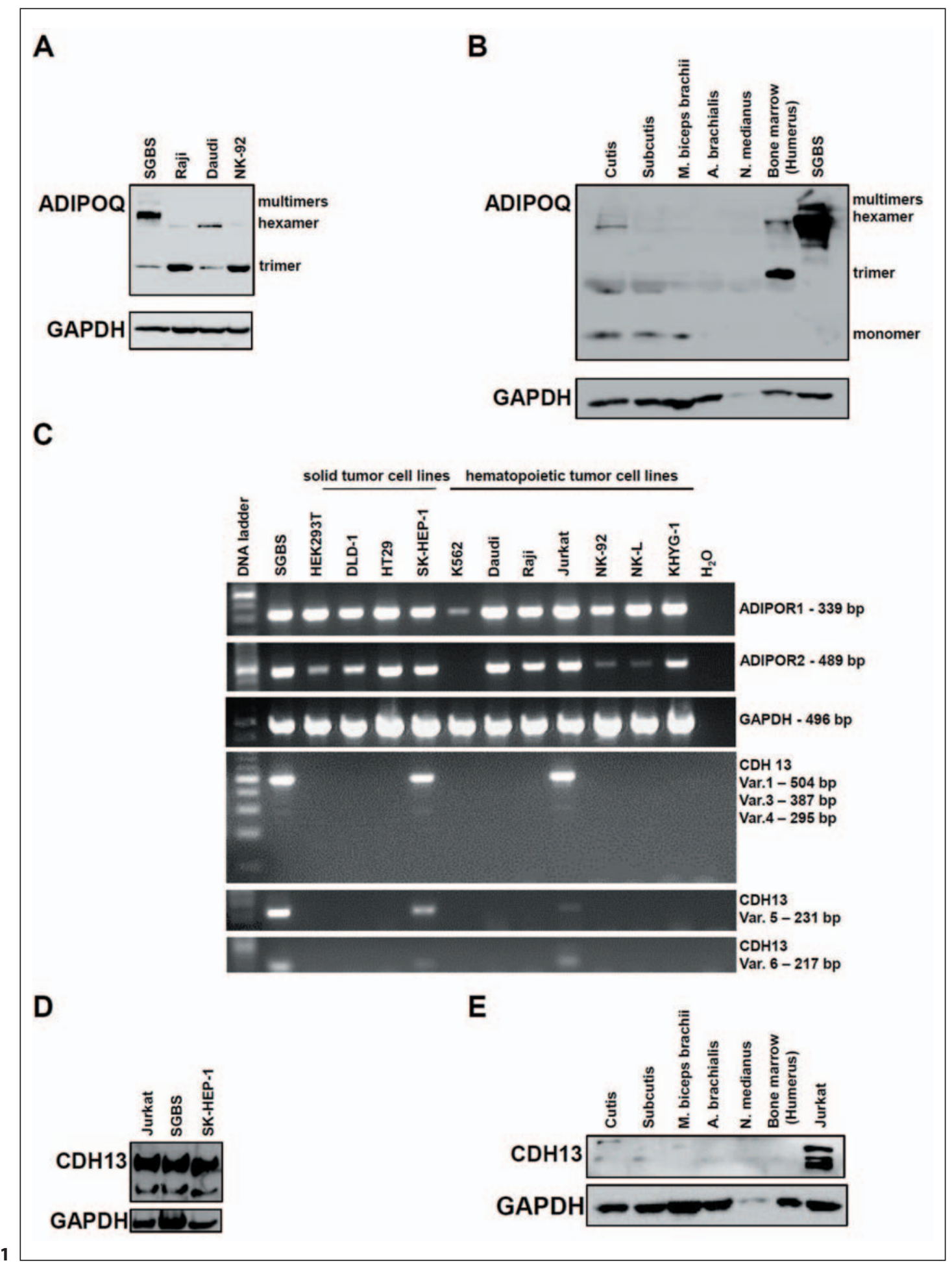

(For legend see next page.) 
not detectable. The observed quaternary protein structures of adiponectin ranged from monomers to homo-multimers, whereas in all investigated human cell lines no monomers could be detected despite equal reducing and denaturating conditions used. Indeed, it has been reported in literature that for destruction of the very stable AdipoQ homomers special denaturating conditions have to be applied [24].

\section{Expression of the AdipoQ Receptors in Human Cell Lines and Frozen Human Tissues}

First, the expression of the three different adiponectin receptors, including the six protein coding CDH13 splice variants, was investigated in the various human cell lines by semi-quantitative PCR (fig. 1C).

While AdipoR1 was expressed in all tested cell lines, AdipoR2 was not detectable in K562 cells, which showed also a reduced AdipoR1 expression, when compared to the other cell lines. The CDH13 expression was only observed in SGBS, SK-HEP-1, and Jurkat cells. The splice variant 1 was the most abundant CDH13 splice variant, followed by splice variant 5 , whereas the splice variants 4 and 6 were weakly expressed and the splice variant 2 could not be detected at all. The three CDH13-positive cell lines can be ordered for their expression of the two shorter splice variants \#5 and \#6 as follows: SGBS > SK-HEP-1 > Jurkat cells.

Western-Blot analyses of the three CDH13-positive cell lines and of the dissected human arm tissues are shown in fig. 1D and fig. 1E using the rabbit polyclonal anti-CDH13 antibody, which recognizes $\mathrm{CDH} 13$ at the cadherin 1 domain allowing the detection of the $\sim 130 \mathrm{kDa}$ pro-protein and the proteolytically cleaved $\sim 105 \mathrm{kDa}$ mature isoform [20]. This cleavage occurs at protein level and therefore is independent of the alternative splicing, generating the six different protein-encoding splice variants at the transcript level. To our knowledge, no CDH13 antibody is available, detecting also the proteins of the shorter splice variants \#5 and \#6. In the dissected human arm tissues, the CDH13 protein was only barely detectable in the cutis.

Interestingly, immunohistochemical staining of paraffin-embedded skin tissues (gluteal region) revealed that $\mathrm{CDH} 13$ protein is only expressed in the stratum basale.

Fig. 1. Analysis of adiponectin and CDH13 expression. A Western-Blot analysis of adiponectin protein levels of the 4 adiponectin positive human cell lines. The human pre-adipocytes SGBS exerted highest expression of adiponectin, especially of the homo-multimers and to a lower extend of the homo-trimers, while the other cell lines only expressed adiponectin homo-hexamers and homo-trimers. The other applied eight human cell lines were adiponectin negative (transcript and protein). B In tissue samples of a non-formalin-fixed frozen human arm the adiponectin expression was determined by Western-blot. As positive control human SGBS cells were also loaded. In opposite of the in vitro data obtained from the cell lines (fig. 1A) also the adiponectin monomers could be detected. No adiponectin could be observed in the arteria brachialis and in the median nerve. In cutis, subcutis and in the skeletal muscle Musculus biceps brachii a weak adiponectin expressed could be determined. The highest adiponectin expression was observed in the bone marrow of the humerus, with adiponectin homo-trimers as most abundant quaternary protein structure. $\mathbf{C}$ The products of semi-quantitative qPCRs were loaded onto a $2 \%(\mathrm{w} / \mathrm{V})$ agarose gel. While the adiponectin receptor 1 was detectable in all applied human cell lines, the adiponectin receptor 2 was not detectable in K562 cells. Only three cell lines expressed CDH13 transcript. All six protein-coding CDH13 mRNA splice variants were investigated, while splice variant 2 could not be detected, all other isoforms were expressed in the three CDH13 positive cell lines SGBS, SK-HEP-1 and Jurkat. D-E Western-blot analyses of CDH13 protein. Only three of the investigated cell lines were positive for CDH13 protein (Jurkat, SGBS, SKHEP-1). Regarding the tissue samples of the frozen human arm, only a barely detectable expression of CDH13 was obtained in cutis, subcutis and skeletal muscle. The antibody recognizes the $\sim 130 \mathrm{kDa}$ pro-protein and the proteolytically cleaved $\sim 105$ $\mathrm{kDa}$ mature isoform. The cleavage occurs at protein level and therefore is independent of the alternative splicing. To our knowledge there is at the moment no CDH13 antibody available, that detects also the proteins of the shorter splice variants \#5 and \#6. 
Jasinski-Bergner et al.: Adiponectin and Its Receptors Are Differentially Expressed in Human Tissues and Cell Lines of Distinct Origin

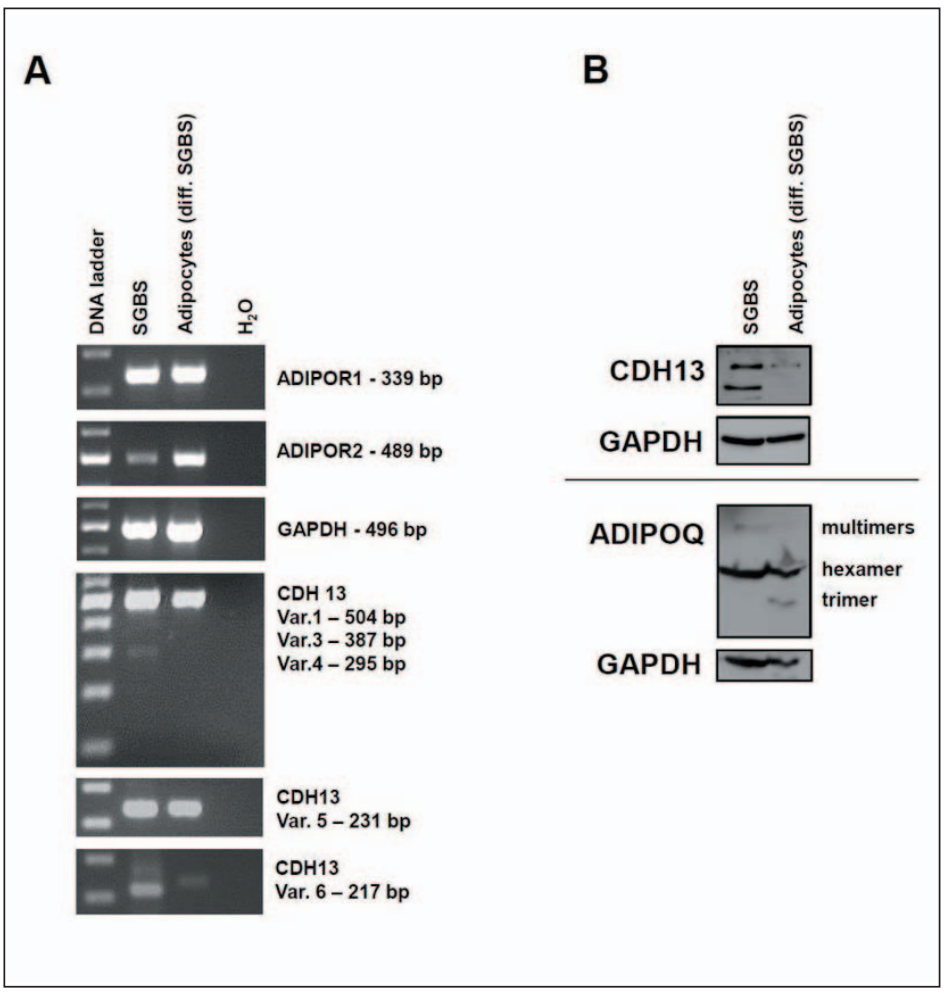

Fig. 2. Analysis of the expression of adiponectin and its receptors in SGBS pre-adipocytes and in adipocytes. A The Semi-quantitative qPCR analysis of the different adiponectin receptors including the CDH13 splice variants shows equal expression of ADIPOR1, enhanced expression of ADIPOR2 in adipocytes and decreased expression of several CDH13 splice variants (Var. 1, 3, 4, 6). The CDH13 splice variant Var. 2 could not be detected in both cell lines. B The Western-Blot analysis of the CDH13 and adiponectin revealed, in analogy to the transcript analysis, a reduced expression of CDH13 in adipocytes. The antibody recognizes the $\sim 130 \mathrm{kDa}$ pro-protein and the proteolytically cleaved $\sim 105 \mathrm{kDa}$ mature isoform. A cleavage, that occurs at protein level and therefore is independent of the alternative splicing. The adiponectin expression was not altered in quantity. In analogy to the other tested cell lines no monomers could be detected.

The expression of $\mathrm{CDH} 13$ and the distribution of its splice variants as well as the expression of ADIPOR1 and ADIPOR2 was further analyzed in SGBS preadipocytes and in differentiated adipocytes (fig. 2).

\section{Adiponectin Expression in Human Myocard, Kidney, and Skin}

The expression of ADIPOQ was further analyzed in 21 paraffin-embedded tissue samples of myocard, kidney, and skin of human body donors. The respective tissue samples from 21 formalin-fixed human body donors were collected and screened by immunohistochemistry using the murine monoclonal anti-adiponectin (19F1) antibody. The expression levels of ADIPOQ in myocard were further scored, and the respective pictures and the percentual distributions are shown in fig. 3A. The expression ranged from barely detectable to strong expression levels, with two-thirds of the samples showing a medium or strong ADIPOQ expression intensity. Based on the information of the certificates of death, the ADIPOQ expression was further compared in males and females (fig. 3B), in two age cohorts (fig. 3C), and for known cardiovascular diseases versus unknown status (fig. 3D). In these comparisons, no statistical differences between the cohorts could be detected. 
Fig. 3. Analysis of AdipoQ expression and correlation to clinical parameters in situ. A Representative immunohistochemical stainings of adiponectin in 21 human myocard tissue samples grouped for their expression levels ranging from barely detectable to strong expression and the percental distribution. B-D Correlation of the adiponectin protein levels of the 21 human myocard samples for gender, age and known cardiovascular diseases. E Representative immunohistochemical stainings of adiponectin in 21 human renal tissue samples grouped for their expression levels ranging from barely detectable to strong expression and the percental distribution. F-H Correlation of the adiponectin protein levels of the 21 human renal tissue samples for gender, age and known renal diseases, with a statistically significant higher adiponectin expression in the group with known renal diseases when compared to the group with unknown status. I Representative immunohistochemical stainings of adiponectin in 21 human skin tissue samples grouped for their expression levels ranging from weak detectable to strong expression and the percental distribution. J-K Correlation of the adiponectin protein levels of the 21 human skin tissue samples for gender and age. The number of samples of the diagrams is expressed in table 3.

Jasinski-Bergner et al.: Adiponectin and Its Receptors Are Differentially Expressed in Human Tissues and Cell Lines of Distinct Origin

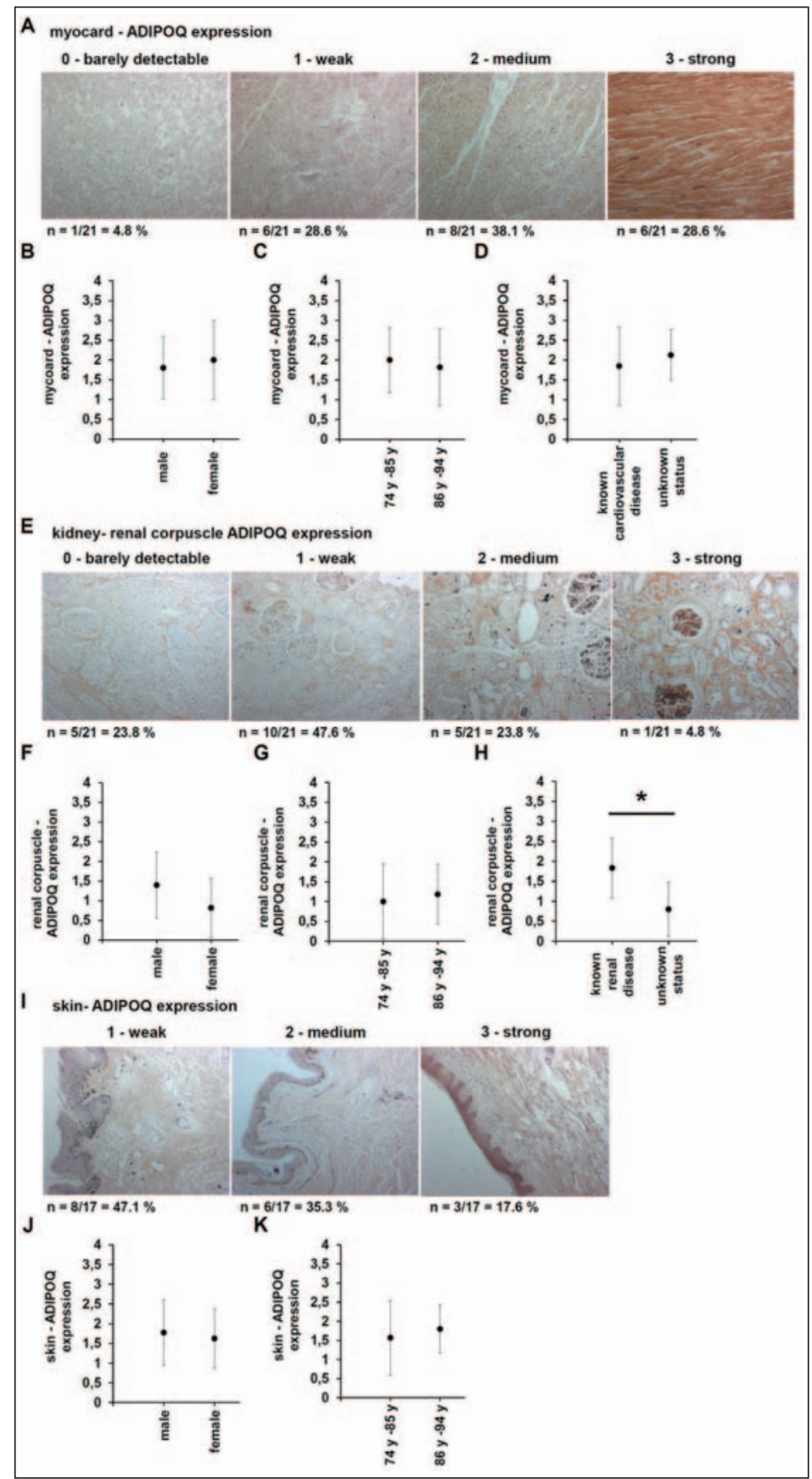

The same procedure was also performed for the analysis of the ADIPOQ expression in human kidneys including the renal corpuscles.

As shown in fig. 3E, the ADIPOQ expression level in the renal corpuscle ranged from barely detectable to strong expression levels. While no gender- or age-dependent ADIPOQ expression in the renal corpuscle could be observed, the expression of ADIPOQ was significantly higher in the group with known renal diseases when compared to the group with the unknown status.

ADIPOQ expression was also detectable in skin (gluteal region), ranging from weak to strong expression, without any differences dependent to gender or age (fig. 3I-K). 


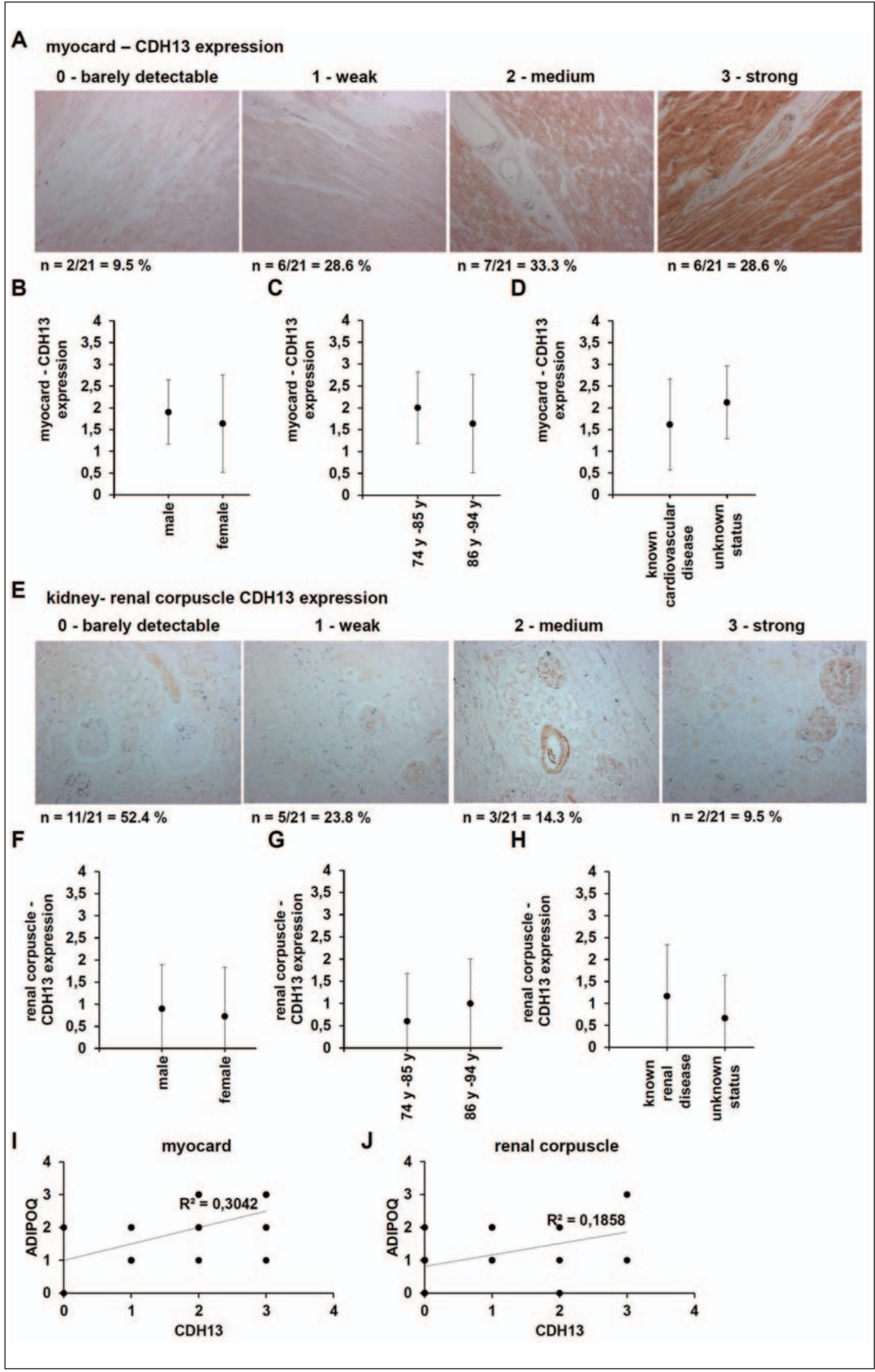

(For legend see next page.) 
Jasinski-Bergner et al.: Adiponectin and Its Receptors Are Differentially Expressed in Human Tissues and Cell Lines of Distinct Origin

\section{CDH13 Expression in Human Myocard and Kidney and Correlation with the Respective ADIPOQ Expression}

The expression of CDH13 in human myocard ranged from barely detectable to strong, with almost $62 \%$ of the samples showing medium and strong expression (fig. $4 \mathrm{~A}$ ). However, regarding gender, age, or known cardiovascular diseases of the human body donors, no statistically significant differences could be observed (fig. 4B-D).

In contrast to the results of the myocard, the expression of $\mathrm{CDH} 13$ in the renal corpuscle was much weaker: $76 \%$ of the investigated samples showed only barely detectable or weak CDH13 expression. In analogy to the results of the CDH13 expression in the myocard, no differences in the expression with regard to gender, age, or known renal diseases of the human body donors were detected (fig. 4E-H). In the skin samples, the CDH13 expression was only detectable in the stratum basale. Within the 21 samples of myocard and kidney, the expression profiles of ADIPOQ and CDH13 were further correlated. While CDH13 and ADIPOQ expression seem to correlate within the 21 myocard samples (fig. $4 \mathrm{I} ; \mathrm{R}^{2}=0.3042$ ), no correlation could be observed for the 21 renal immunohistochemical stainings (fig. 4J; $\mathrm{R}^{2}=0.1858$ ).

\section{Analysis of the Expression of Adiponectin and Its Receptors in Immune Effector Cell}

Populations

Th cells, CTLs, NK cells, B cells, and monocytes were sorted by flow cytometry from PBMCs isolated from the blood of three healthy human blood donors. For every immune effector cell population, $1 \times 10^{6}$ cells were sorted. The sorted cell populations were subsequently re-analyzed by flow cytometry for a first analysis of the respective purities (fig. 5A-E).

Afterwards the total RNA was extracted, and cDNA synthesis was performed for analysis of the expression of adiponectin, its receptors and, in case of $\mathrm{CDH} 13$, the respective splice variants. As an additional control for the purity of the respective immune effector cell populations, certain marker genes, including CD4, CD8, CD56, CD20 and CD14, were also analyzed by semi-quantitative PCR. Every single marker could be detected only in the respective immune effector cell

Table 3. List of the absolute sample numbers presented in diagrams in figures 2 and 3

\begin{tabular}{llllll}
\hline Figure & $\begin{array}{l}\text { No. } \\
\text { (1st group) }\end{array}$ & $\begin{array}{l}\text { No. } \\
\text { (2nd group) }\end{array}$ & Figure & $\begin{array}{l}\text { No. } \\
\text { (1st group) }\end{array}$ & $\begin{array}{l}\text { No. } \\
\text { (2nd group) }\end{array}$ \\
\hline 2B & 10 & 11 & $3 \mathrm{~B}$ & 10 & 11 \\
2C & 10 & 11 & $3 \mathrm{C}$ & 10 & 11 \\
2D & 13 & 8 & $3 \mathrm{D}$ & 13 & 8 \\
2F & 10 & 11 & $3 \mathrm{~F}$ & 10 & 11 \\
2G & 10 & 11 & $3 \mathrm{G}$ & 10 & 11 \\
2H & 6 & 15 & $3 \mathrm{H}$ & 6 & 15 \\
2J & 9 & 8 & $3 \mathrm{I}$ & 21 & \\
2K & 7 & 10 & $3 \mathrm{~J}$ & 21 & \\
\hline
\end{tabular}

Fig. 4. Analysis of CDH13 expression and correlation to clinical parameters in situ. A Representative immunohistochemical stainings of CDH13 in 21 human myocard tissue samples grouped for their expression levels ranging from barely detectable to strong expression and the percental distribution. B-D Correlation of the CDH13 protein levels of the 21 human myocard samples for gender, age and known cardiovascular diseases. E Representative immunohistochemical stainings of CDH13 in 21 human renal tissue samples grouped for their expression levels ranging from barely detectable to strong expression and the percental distribution. F-H Correlation of the CDH13 protein levels of the 21 human renal tissue samples for gender, age and known renal diseases. I-J Correlation of the adiponectin and CDH13 protein levels (immunohistochemical stainings) in the 21 human myocard (I) and in the 21 human renal tissue samples (J) and the respective coefficient. The number of samples of the diagrams is expressed in table 3. 
Fig. 5. Characterization of the expression of AdipoQ and its receptors in immune effector cell populations of healthy human blood donors. A-E Representative analyses of the sorted immune effector cell populations of peripheral blood from 1 of 3 healthy blood donors by flow cytometry. F Analysis of the expression of AdipoQ and its receptors in certain immune effector cell population by semi-quantitative qPCR. ADIPOR2 and CDH13 were not detectable in the purified immune effector cell populations. In addition, as quality control of the sorted immune cell populations, the respective cluster of differentiation markers were also analyzed.

Jasinski-Bergner et al.: Adiponectin and Its Receptors Are Differentially Expressed in Human Tissues and Cell Lines of Distinct Origin

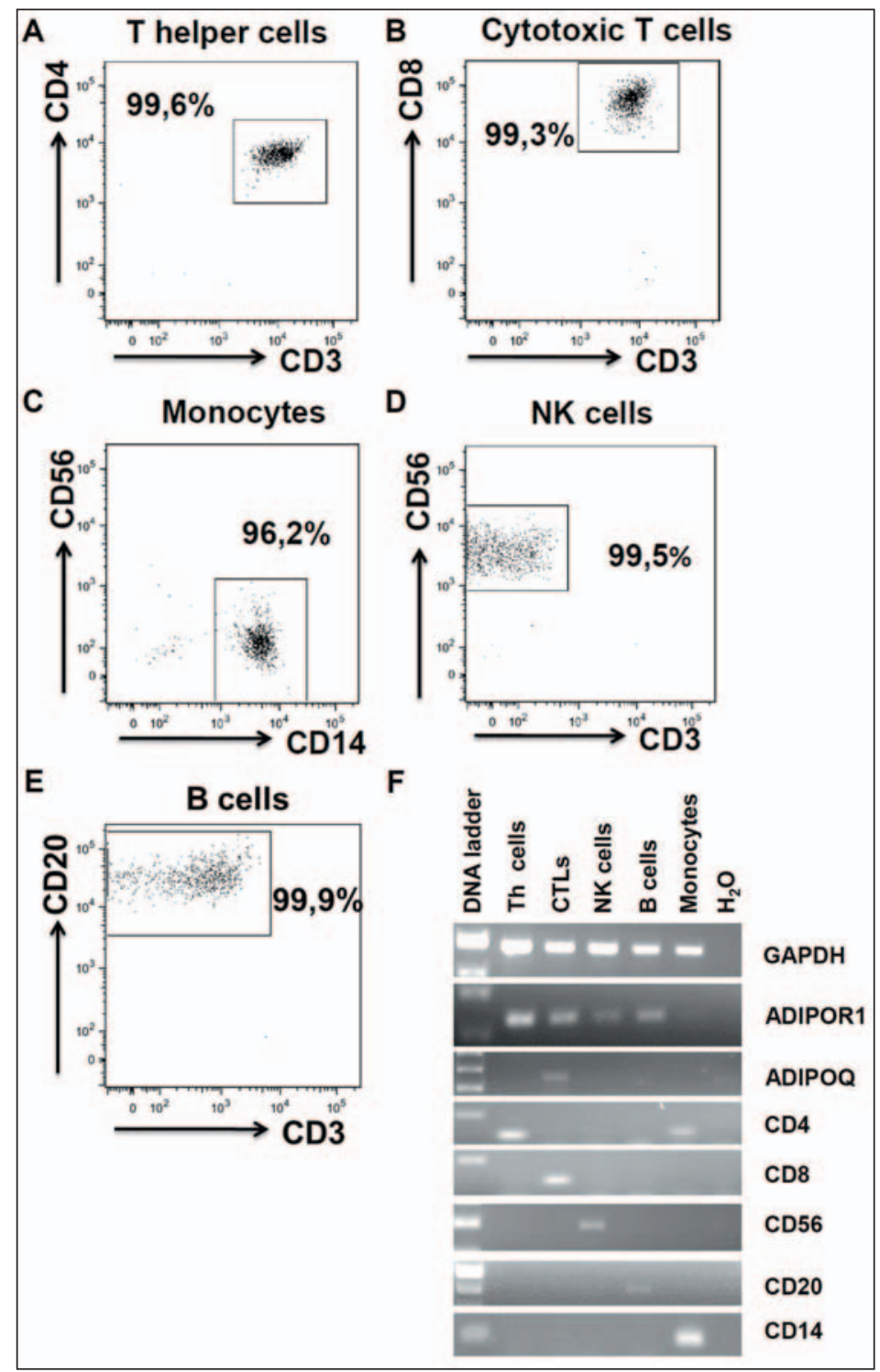

population, proofing again the purity of the sorted immune effector cell populations. Indeed, monocytes were also weakly positive for CD4, but by far weaker than Th cells as expected.

In analogy to the results of the human tumor cell lines, ADIPOR1 was expressed in all immune effector cell populations, but was only barely detectable in monocytes. Adiponectin was only expressed in CTLs. CDH13 and ADIPOR2 were not expressed in the immune effector cell populations.

\section{Discussion}

To date three different adiponectin receptors have been identified: AdipoR1, AdipoR2, and recently $\mathrm{CDH} 13$, binding to distinct quaternary protein structures of adiponectin. However, it is unclear thus far if all of the six protein-encoding CDH13 isoforms result in proteins able to bind adiponectin protein. And even more important, it is not clear whether 
or not adiponectin and its receptor $\mathrm{CDH} 13$ are expressed in non-tumorous human tissues. So far, only little is known about this point, and our knowledge is mostly restricted to selected animal tissues or to human in vitro cell lines or tissue fluids with even lower cohort sizes than provided by this study.

Therefore, the present study aimed to investigate the expression of adiponectin and its receptor $\mathrm{CDH} 13$ in various human tissues, including heart, liver, kidney, spleen, skin, blood vessels, peripheral nerve, and bone marrow as well as in a set of 12 human cell lines. As expected, we could detect a high expression of adiponectin in the bone marrow. Indeed the bone marrow adipose tissue is already reported to express adiponectin [25]. Additionally, adiponectin expression was also observed in certain lymphatic tumor cell lines. Therefore, we further investigated the expression of adiponectin and its receptors in purified immune effector cell populations such as Th cells, CTLs, NK cells, B cells, and monocytes of healthy human blood donors. Indeed, we could detect adiponectin transcripts exclusively in CD3+ CD8+ CTLs.

In addition, we were able to detect adiponectin in all three kinds of musculature, including smooth muscle within the blood vessels, skeletal muscle, and heart muscle of the myocard of the left ventricle.

It is noteworthy that due to the fixation process of the human body donors most of the blood and the serum including the circulating adiponectin within the blood vessels were removed.

Regarding the adiponectin expression in the human myocard strong differences between the 21 human samples were obtained ranging from barely detectable to strong expression, which is quite important when considering that some studies were based on only small numbers of tissues of autopsy specimens.

However, about $70 \%$ of the investigated myocard samples exerted medium to strong expression. By correlating these data to certain clinical parameters, including gender, age (limited due to donor age ranging from 74 to 96 years) and known cardiovascular diseases versus unknown status, no significant differencewas observed. Adiponectin was reported to exert favorable effects to angiogenesis and to endothelial functions as shown in animal studies using adiponectin knockout and overexpression mutants [26]. Furthermore, it could be demonstrated that adiponectin knockout mice developed larger myocardial infarct sizes when compared to wild-type mice [27]. This observation does not necessarily interfere with our observations due to the fact that we compared all known cardiovascular diseases as one group versus a group with unknown status due to the fact of limited information available for the human body donors. Moreover, the murine knockout mutants must not necessarily reflect physiological situations, including indirect effects of the ADIPOQ knockout per se. Another study investigating the expression of adiponectin and $\mathrm{CDH} 13$ in damaged cardiomyocytes in autopsy specimens by immunohistochemistry also reported no significant difference in the detection of these molecules in the cardiomyocytes, which is in line with our observations. However, this study further showed only a weak expression of CDH13 and no expression of adiponectin in the healthy control group comprising of only 4 samples [28]. This is in contrast to our study, where the expression ranged from barely detectable to strong in both study groups. It is noteworthy that in the above-mentioned study a different anti-adiponectin antibody was used: the rabbit polyclonal anti-human adiponectin (AB3784P, Chemicon International Inc., Temecula, CA, USA).

In liver and spleen, adiponectin expression was only detected in the smooth musculature of the blood vessels, but not within the respective parenchyma (data not shown).

Furthermore, ADIPOQ expression was investigated in human kidneys with a special focus on the renal corpuscle where the filtration of the primary urine takes place. Indeed, many kidney diseases are nephropathies with damaged or reduced functional nephrons. Nephrogenesis occurs before birth, and after birth mammalian damaged kidney usually does not 
Jasinski-Bergner et al.: Adiponectin and Its Receptors Are Differentially Expressed in Human Tissues and Cell Lines of Distinct Origin

have any regenerative properties [29]. In the process of nephropathies, connective tissue can infiltrate the renal corpuscle, which negatively interferes with the glomerular filtration functionality. This could explain why the highest ADIPOQ expression was significantly linked with renal diseases within the investigated human tissue samples.

Interestingly, in the myocard samples the expression of the recently discovered ADIPOQ receptor CDH13 correlated to the expression of ADIPOQ. This correlation was much weaker in the case of the renal corpuscles and was completely lacking in the bone marrow or within the purified immune effector cell populations.

In the investigated human cell lines, we were not able to detect the mRNA of the CDH13 splicing variant 2 containing an additional exon in the $5^{\prime}$ direction of the CDS, which results in a longer protein than isoform 1 , by semi-quantitative PCR .

Further studies should investigate in more detail the role of adiponectin in obesity-linked immune deficiency and its role as potential marker in nephropathies.

For the first time, the expression profiles of the anti-inflammatory adipokine ADIPOQ and its receptor $\mathrm{CDH} 13$ was analyzed in a set of human in vivo and in vitro tissue samples to obtain more information about the connection between obesity and immune deficiency - a medical issue of increasing and already enormous economical relevance.

\section{Acknowledgments}

We would like to thank Susann Möschter and Franziska Knöfel for excellent technical assistance and Nneka Schwimmer-Okike from the institute of Forensic Medicine of the Martin Luther University HalleWittenberg for consulting.

Furthermore we want to express deep respect to the human body donors for existential contribution in teaching and science at the institute of Anatomy and Cell Biology of the Martin Luther University HalleWittenberg.

The SGBS cells and the corresponding differentiated adipocytes were kindly provided by Prof. Anne Navarette Santos (Institute of Anatomy and Cell Biology, Faculty of Medicine, Martin Luther University HalleWittenberg).

\section{Grants}

This work was performed with a grant of the Dr. Werner Jackstädt Foundation.

\section{Disclosure Statement}

The authors have declared that no conflict of interest exists.

\section{References}

1 Guenther D, Schmidl S, Klatte TO, Widhalm HK, Omar M, Krettek C, Gehrke T, Kendoff D, Haasper C: Overweight and obesity in hip and knee arthroplasty: evaluation of 6078 cases. World J Orthop 2015;6:137-144.

2 Ouchi N, Parker JL, Lugus JJ, Walsh K: Adipokines in inflammation and metabolic disease. Nat Rev Immunol 2011;11:85-97.

3 Van Gaal LF, Mertens IL, De Block CE: Mechanisms linking obesity with cardiovascular disease. Nature 2006; 444:875-880.

4 Lehr S, Hartwig S, Lamers D, Famulla S, Muller S, Hanisch FG, Cuvelier C, Ruige J, Eckardt K, Ouwens DM, Sell $\mathrm{H}$, Eckel J: Identification and validation of novel adipokines released from primary human adipocytes. Mol Cell Proteomics 2011;11:M111.010504.

5 Scherer PE: Adipose tissue: from lipid storage compartment to endocrine organ. Diabetes 2006;55:1537-1545. 
6 Waki H, Tontonoz P: Endocrine functions of adipose tissue. Annu Rev Pathol 2007;2:31-56.

7 Lehr S, Hartwig S, Sell H: Adipokines: a treasure trove for the discovery of biomarkers for metabolic disorders. Proteomics Clin Appl 2012;6:91-101.

8 Roberts DL, Dive C, Renehan AG: Biological mechanisms linking obesity and cancer risk: new perspectives. Annu Rev Med 2010;61:301-316.

9 Ohashi K, Shibata R, Murohara T, Ouchi N: Role of anti-inflammatory adipokines in obesity-related diseases. Trends Endocrinol Metab 2014;25:348-355.

10 Yokota T, Oritani K, Takahashi I, Ishikawa J, Matsuyama A, Ouchi N, et al: Adiponectin, a new member of the family of soluble defense collagens, negatively regulates the growth of myelomonocytic progenitors and the functions of macrophages. Blood 2000;96:1723-1732.

11 Yamaguchi N, Argueta JG, Masuhiro Y, Kagishita M, Nonaka K, Saito T, et al: Adiponectin inhibits Toll-like receptor family-induced signaling. FEBS Lett 2005;579:6821-6826.

12 Okamoto Y, Folco EJ, Minami M, Wara AK, Feinberg MW, Sukhova GK, et al: Adiponectin inhibits the production of CXC receptor 3 chemokine ligands in macrophages and reduces T-lymphocyte recruitment in atherogenesis. Circ Res 2008;102:218-225.

13 Kim KY, Kim JK, Han SH, Lim JS, Kim KI, Cho DH, et al: Adiponectin is a negative regulator of NK cell cytotoxicity. J Immunol 2006;176:5958-5964.

14 Kadowaki T, Yamauchi T: Adiponectin and adiponectin receptors. Endocr Rev 2005;26:439-451.

15 Yamauchi T, Kamon J, Ito Y, Tsuchida A, Yokomizo T, Kita S, et al: Cloning of adiponectin receptors that mediate antidiabetic metabolic effects. Nature 2003;423:762-769.

16 Hug C, Wang J, Ahmad NS, Bogan JS, Tsao TS, Lodish HF: T-cadherin is a receptor for hexameric and highmolecular-weight forms of Acrp30/adiponectin. Proc Natl Acad Sci U S A 2004;101:10308-10313.

17 Ciatto C, Bahna F, Zampieri N, VanSteenhouse HC, Katsamba PS, Ahlsen G, et al: T-cadherin structures reveal a novel adhesive binding mechanism. Nat Struct Mol Biol 2010;17:339-347.

18 Dames SA, Bang E, Haussinger D, Ahrens T, Engel J, Grzesiek S: Insights into the low adhesive capacity of human T-cadherin from the NMR structure of Its N-terminal extracellular domain. J Biol Chem 2008;283: $23485-23495$.

19 Hebbard LW, Garlatti M, Young LJ, Cardiff RD, Oshima RG, Ranscht B: T-cadherin supports angiogenesis and adiponectin association with the vasculature in a mouse mammary tumor model. Cancer Res 2008;68:14071416.

20 Denzel MS, Scimia MC, Zumstein PM, Walsh K, Ruiz-Lozano P, Ranscht B: T-cadherin is critical for adiponectinmediated cardioprotection in mice. J Clin Invest120:4342-4352.

21 Philippova M, Joshi MB, Kyriakakis E, Pfaff D, Erne P, Resink TJ: A guide and guard: the many faces of T-cadherin. Cell Signal 2009;21:1035-1044.

22 Wabitsch M, Brenner RE, Melzner I, Braun M, Moller P, Heinze E, et al: Characterization of a human preadipocyte cell strain with high capacity for adipose differentiation. Int J Obes Relat Metab Disord 2001;25:8-15.

23 Jasinski-Bergner S, Stoehr C, Bukur J, Massa C, Braun J, Huttelmaier S, et al: Clinical relevance of miR-mediated HLA-G regulation and the associated immune cell infiltration in renal cell carcinoma. Oncoimmunology 2015; 4:e1008805.

24 Pajvani UB, Du X, Combs TP, Berg AH, Rajala MW, Schulthess T, et al: Structure-function studies of the adipocyte-secreted hormone Acrp30/adiponectin. Implications fpr metabolic regulation and bioactivity. J Biol Chem 2003;278:9073-9085.

25 Cawthorn WP, Scheller EL, Learman BS, Parlee SD, Simon BR, Mori H, et al: Bone marrow adipose tissue is an endocrine organ that contributes to increased circulating adiponectin during caloric restriction. Cell Metab 2014;20:368-375.

26 Shibata R, Ouchi N, Kihara S, Sato K, Funahashi T, Walsh K: Adiponectin stimulates angiogenesis in response to tissue ischemia through stimulation of amp-activated protein kinase signaling. J Biol Chem 2004;279: 28670-28674.

27 Shibata R, Sato K, Pimentel DR, Takemura Y, Kihara S, Ohashi K, et al: Adiponectin protects against myocardial ischemia-reperfusion injury through AMPK- and COX-2-dependent mechanisms. Nat Med 2005;11:10961103.

28 Takahashi T, Saegusa S, Sumino H, Nakahashi T, Iwai K, Morimoto S, et al: Adiponectin, T-cadherin and tumour necrosis factor-alpha in damaged cardiomyocytes from autopsy specimens. J Int Med Res 2005;33:236-244.

29 McCampbell KK, Wingert RA: Renal stem cells: fact or science fiction?. Biochem J 2012;444:153-168.

30 Mocellin S, Provenzano M, Rossi CR, Pilati P, Nitti D, Lise M: Use of quantitative real-time PCR to determine immune cell density and cytokine gene profile in the tumor microenvironment. J Immunol Methods 2003;280: 1-11.

31 Henry C, Deschamps M, Rohrlich PS, Pallandre JR, Remy-Martin JP, Callanan M, Traverse-Glehen A, GrandClément C, Garnache-Ottou F, Gressin R, Deconinck E, Salles G, Robinet E, Tiberghien P, Borg C, Ferrand C: Identification of an alternative CD20 transcript variant in B-cell malignancies coding for a novel protein associated to rituximab resistance. Blood 2010;115:2420-2429. 